\title{
Utilization of transferrin and salmon serum as sources of iron by typical and atypical strains of Aeromonas salmonicida
}

\author{
Ian D. Hirst and Anthony E. Ellis \\ Author for correspondence: A. E. Ellis. Tel: +441224 876 544. Fax: +441224295511.
}

SOAFD, Marine Laboratory, PO Box 101, Victoria Road, Aberdeen AB9 8DB, UK

\begin{abstract}
The ability of typical and atypical strains of Aeromonas salmonicida to utilize non-haem sources of protein-bound iron was evaluated. (i) In a plate bioassay, the suppression of growth imposed on typical and atypical A. salmonicida by addition of the high-affinity iron chelator ethylenediamine-di(ohydroxyphenylacetic acid) (EDDA) to the growth medium was reversed by the addition of $30 \%$ or $90 \%$ iron-saturated bovine or human transferrin (Tf) or lactoferrin (Lf) to the growth medium. (ii) The mechanism of obtaining iron from $\mathrm{Tf}$ was investigated by the addition of bovine $\mathrm{Tf}$ contained within a dialysis bag. The reversal of iron-restricted growth suppression differed between the strains in that the atypical strains were unable to utilize Tf contained within a dialysis bag while the typical strains were able to do so. This suggested a siderophore-mediated uptake of iron from Tf by the typical strains, which are known to produce siderophores while atypical strains do not. (iii) A solid-phase binding assay using horseradish-peroxidase-conjugated or biotinylated Tf or Lf failed to detect Tf/Lf-binding activity using whole typical or atypical cells. (iv) When atypical extracellular products (ECP) plus bovine if or salmon serum were enclosed in a dialysis bag, diffusible products were released which could reverse the EDDA-imposed growth suppression of an atypical strain. This reversal was negated by inhibition of the ECP metalloprotease with EDTA. (v) Purified $70 \mathrm{kDa}$ serine protease of a typical strain was able to digest bovine Tf to low molecular mass fragments as observed in SDS-PAGE. These results indicate that typical and atypical strains of A. salmonicida differ in their mechanism of utilization of non-haem proteinbound sources of iron. Typical strains utilize Tf via a siderophore-mediated mechanism and are also able to digest If with the extracellular serine protease. Atypical strains utilize if by a siderophore-independent mechanism probably involving the proteolytic degradation of $\mathrm{Tf}$ by the extracellular metalloprotease.
\end{abstract}

Keywords: Aeromonas salmonicida, iron acquisition, transferrin, lactoferrin.

\section{INTRODUCTION}

An important factor in bacterial pathogenicity and virulence is the ability of invading pathogens to grow and multiply rapidly in vivo by overcoming specific and nonspecific host defence mechanisms (Smith, 1990). Although the host contains large amounts of iron, the levels of free

Abbreviations: ECP, extracellular products; EDDA, ethylenediamine-di(ohydroxyphenylacetic acid); HRP, horseradish peroxidase; IROMPs, ironregulated outer-membrane proteins; Lf, lactoferrin; Tf, transferrin. ionic iron $\left(\mathrm{Fe}^{3+}\right)$ are maintained at very low concentrations due to sequestration by the host iron-binding glycoproteins: transferrin ( $\mathrm{Tf}$ ) in serum and extracellular fluids and lactoferrin (Lf) on mucosal surfaces. These iron-binding glycoproteins have high association constants for $\mathrm{Fe}^{3+}$ of the magnitude $10^{36} \mathrm{M}$ (Griffiths, 1987 a) and are only partially saturated with iron. This results in the amount of free iron in vivo (approximately $10^{-18} \mathrm{M}$ ) being insufficient for bacterial growth. Because bacteria have an absolute requirement for iron (Bullen, 1981), successful pathogens must possess iron uptake 
mechanism(s) which effectively overcome the host's ironsequestering mechanisms in order to grow and multiply in vivo.

Most pathogenic bacteria growing under conditions of iron restriction in vitro possess high-affinity iron uptake mechanisms capable of removing iron for growth from $\mathrm{Tf}$ and Lf (Griffiths et al., 1988; Martinez et al., 1990). The most common mechanism, found in many Gram-negative bacteria, involves the production of siderophores (low molecular mass iron chelators) which have high association constants for iron. Uptake of iron into the cell is mediated by specific membrane receptors-ironregulated outer-membrane proteins (IROMPs) not expressed in iron-replete conditions - which recognize the $\mathrm{Fe}^{3+}$-siderophore complex. Certain pathogens such as Neisseria meningitidis (Schryvers \& Morris, 1988), Haemophilus influenzae (Schryvers, 1988) and Pasteurella baemolytica (Ogunnariwo \& Schryvers, 1990) are able to obtain iron by direct cell surface binding of Tf or Lf via IROMPs which recognize $\mathrm{Fe}^{3+}$-Tf or - Lf complexes allowing utilization without siderophore production. It appears that the induction of high-affinity iron uptake mechanisms is essential for the growth of bacterial pathogens during the disease process since both siderophores (Griffiths \& Humphreys, 1980; Wolf \& Crosa, 1986) and IROMPs (Sciortino \& Finkelstein, 1983; Chart \& Griffiths, 1985; Donachie \& Gilmour, 1988) are known to be produced during growth in vivo.

Aeromonas salmonicida, the causative agent of furunculosis, is a successful systemic pathogen of both salmonid and non-salmonid fish. Typical strains of $A$. salmonicida (subspecies salmonicida) are capable of rapid growth in vivo resulting in an acute haemorrhagic septicaemia often associated with extensive liquefaction of host tissues (McCarthy \& Roberts, 1980). Atypical strains of $A$. salmonicida (subspecies acbromogenes) produce a more superficial ulcerative form of furunculosis in both salmonid and non-salmonid fish.

Only typical strains of $A$. salmonicida possess an inducible siderophore-mediated iron uptake mechanism (Hirst et al., 1991), although both typical and atypical strains are able to grow under conditions of iron restriction and express IROMPs (Chart \& Trust, 1983; Aoki \& Holland, 1985). A second non-siderophore iron uptake mechanism has been described by Chart \& Trust (1983) which suggested that direct cell contact with iron-glycoprotein complexes was required.

In this study, the ability of typical and atypical strains of $A$. salmonicida to utilize non-haem sources of proteinbound iron was compared and the possible mechanisms which may enable $A$. salmonicida to obtain iron from Tf and Lf sources and salmon serum were investigated.

\section{METHODS}

A. salmonicida and growth conditions. Four typical and two atypical strains of $A$. salmonicida designated in Table 1 and described elsewhere (Hirst et al., 1991) were used. Seed cultures were grown on Tryptic Soya Agar (TSA; Oxoid) for 24-48 h at $22^{\circ} \mathrm{C}$ and suspended in PBS ( $\left.\mathrm{pH} 7 \cdot 2\right)$ to an $\mathrm{OD}_{540}$ of $1\left(10^{9}\right.$ cells $\mathrm{ml}^{-1}$ ) for further use. For the identification of a putative Tf/Lf-binding protein, $A$. salmonicida was grown in an ironrestricted medium composed of Tryptone Soya Broth (TSB; Oxoid) containing the high-affinity iron chelator EDDA $\left(100 \mu \mathrm{g} \mathrm{ml}^{-1}\right.$, Sigma). Contaminating iron was removed from EDDA by the method of Rogers (1973). When grown under these iron-restricted conditions all six $A$. salmonicida strains express additional IROMPs (data shown in Hirst \& Ellis, 1994). Iron-replete bacteria were grown in TSB lacking EDDA. $A$. salmonicida broth cultures were incubated at $22{ }^{\circ} \mathrm{C}$ for $48 \mathrm{~h}$ on a rotary shaker. In dialysis bag experiments involving inhibition of the extracellular protease of an atypical strain by EDTA, TSB (Gibco) was used. The atypical strains grew to a higher cell density in Gibco TSB than in Oxoid TSB.

Transferrins (Tf) and lactoferrins (Lf). Purified human and bovine Tfs and Lfs were obtained from Sigma and prepared in the apo-form by the method of Aisen $e$ al. (1978). ApoTf and Lf were saturated to $30 \%$ (the physiological saturation of Tf; Bezkorovainy, 1987) and $90 \%$ by the addition of a calculated amount of ferric citrate and the percentage iron saturation measured by the method of Graham \& Bates (1976).

Salmon serum. Four Atlantic salmon, Salmo salar, were anaesthetized with MS222 (Sigma) and bled from the caudal vein. Blood was allowed to clot at room temperature and centrifuged. Non-haemolysed serum was collected, pooled and stored at $-80^{\circ} \mathrm{C}$ until used.

Determination of iron levels in Atlantic salmon serum. Serum iron levels of Atlantic salmon were determined in order to quantify the amounts of uncomplexed ferric iron available to $A$. salmonicida during infection. Serum iron levels were measured using an iron and total iron-binding capacity kit (Sigma) based on the method described by Persijn et al. (1971). Free serum iron levels were measured using a bleomycin assay described by Gutteridge et al. (1981).

Growth of $A$. salmonicida in salmon serum. A. salmonicida was inoculated into heat-inactivated $\left(45^{\circ} \mathrm{C}\right.$ for $\left.30 \mathrm{~min}\right)$ Atlantic salmon serum at a concentration of $3 \times 10^{3}$ c.f.u. $\mathrm{ml}^{-1}$ and incubated at $22^{\circ} \mathrm{C}$ for $48 \mathrm{~h}$. Growth of $A$. salmonicida was monitored by taking $20 \mu \mathrm{l}$ samples, making serial 10 -fold dilutions in PBS and inoculating onto TSA plates. The latter were incubated at $22^{\circ} \mathrm{C}$ for $48 \mathrm{~h}$ and the number of c.f.u. $\mathrm{ml}^{-1}$ (mean of three) calculated to give viable counts and the growth rate of $A$. salmonicida in salmon serum.

Utilization of Tf/Lfbound iron. A plate bioassay was used to determine which $\mathrm{Tf} / \mathrm{Lf}$ sources could supply iron to typical and atypical strains of $A$. salmonicida. Approximately $10^{5}$ bacteria were seeded onto TSA containing $200 \mu \mathrm{g} \mathrm{EDDA} \mathrm{m}{ }^{-1}$. Thirty microlitres of a $1 \mathrm{mg} \mathrm{m}^{-1}$ solution of $30 \%$ or $90 \%$ iron-

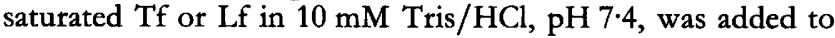
$3 \mathrm{~mm}$ diameter wells punched in the agar. Plates were incubated for $48 \mathrm{~h}$ at $22^{\circ} \mathrm{C}$ and were then examined for stimulation of growth around the wells. ApoTf, ApoLf and $100 \mu \mathrm{M} \mathrm{FeCl}_{3}$ were included as negative and positive controls respectively.

Siderophore-mediated utilization of Tf-bound iron. Experiments to determine whether Tf-iron acquisition by typical and atypical strains of $A$. salmonicida was mediated by a siderophore-dependent mechanism or required direct cell surface contact were carried out as described by Morton \& Williams (1990). A. salmonicida was inoculated (to a concentration of $2 \times 10^{7}$ cells ml ${ }^{-1}$ ) into TSB (Oxoid) containing $200 \mu \mathrm{g}$ EDDA ml ${ }^{-1}$ with or without $30 \%$ iron-saturated bovine 
or human $\mathrm{Tf}\left(1 \mathrm{mg} \mathrm{m} \mathrm{m}^{-\mathbf{1}}\right)$. To some broths, a dialysis bag (Medicell; molecular mass exclusion limit approximately $10 \mathrm{kDa}$ ) containing $1 \mathrm{ml}$ bovine Tf $\left(5 \mathrm{mg} \mathrm{ml}^{-1}\right)$ or TSB was added. Bacteria were incubated at $22^{\circ} \mathrm{C}$ on a rotary shaker and their growth was monitored by $\mathrm{OD}_{540}$ measurement. The four typical and two atypical strains listed in Table 1 were used in this experiment.

Tf-binding assays. A solid-phase dot-blot enzyme assay was used to examine the binding of Tf or Lf to $A$. salmonicida as described by Schryvers \& Morris (1988). Two microlitres of a $48 \mathrm{~h}$ broth culture of iron-replete or iron-restricted whole cells was spotted onto nitrocellulose membranes $(0.45 \mu \mathrm{M}$; Bio-Rad). Iron-restricted cells express IROMPs (Hirst \& Ellis, 1994). Membranes were air-dried at room temperature for $10 \mathrm{~min}$, blocked with $3 \%(\mathrm{w} / \mathrm{v})$ gelatin in Tris-buffered saline (TBS; $50 \mathrm{mM}$ Tris/ $\mathrm{HCl}, 150 \mathrm{mM} \mathrm{NaCl}, \mathrm{pH} \mathrm{7.5)}$ and probed either with horseradish-peroxidase-conjugated Tf or Lf (HRP-Tf, HRP-Lf) prepared by a two-step glutaraldehyde coupling procedure described by Avrameas et al. (1979), or with biotinylated Tf or Lf (bio-Tf, bio-Lf) prepared as described by Morton \& Williams (1990) followed by peroxidase-labelled streptavidin (Sigma). HRP-Tf, HRP-Lf, bio-Tf and bio-Lf immobilized on nitrocellulose in place of whole cells served as positive controls. Dot-blots were developed with a 4-chloro-1naphthol $/ \mathrm{H}_{2} \mathrm{O}_{2}$ substrate kit (Bio-Rad).

Proteolytic degradation of Tf and salmon serum. Experiments to determine whether iron acquisition from $\mathrm{Tf}$ and salmon serum by typical and atypical strains of $A$. salmonicida was mediated by a process involving the extracellular proteases produced by the bacterium were carried out by two methods: the first using dialysis bag experiments, and the second, determining the proteolytic degradation of Tf by SDS-PAGE using a partially purified preparation of an extracellular protease isolated from a typical strain of $A$. salmonicida.

Dialysis bag experiments. The ability of the proteolytic activity of the extracellular products (ECP) of an atypical strain to release iron from $\mathrm{Tf}$ or salmon serum enclosed in a dialysis bag was investigated. ECP of the atypical $A$. salmonicida strain MT525 was prepared by harvesting the supernatant from a $48 \mathrm{~h}$ culture grown on cellophane overlying Brain Heart Infusion Agar (Oxoid) and proteolytic and inhibition assays using hide powder azure as substrate and $10 \mathrm{mM}$ EDTA as inhibitor were performed as described by Gudmundsdottir et al. (1990). EDTA inhibited over $95 \%$ of the proteolytic activity.

Tests with the inhibited protease activity involved mixing ECP $(1 \mathrm{ml})$ plus EDTA $(10 \mathrm{mM})$ with $1 \mathrm{ml} 30 \%$ iron-saturated bovine $\operatorname{Tf}\left(5 \mathrm{mg} \mathrm{ml}^{-1}\right)$ or $1 \mathrm{ml}$ salmon serum and placing this in a dialysis bag which was then immersed in a 200 ml flask of TSB (Gibco) containing $10 \mathrm{mM}$ EDTA. Protease-positive tests $(\mathrm{ECP}+\mathrm{Tf}$ and ECP + salmon serum) and the controls, which included ECP, Tf, salmon serum or TSB, separately, in the bags, omitted the EDTA. The flasks were incubated on a shaker for $16 \mathrm{~h}$ at $22^{\circ} \mathrm{C}$ and then the bags were removed. EDTA was then added to the protease-positive and control flasks (to $10 \mathrm{mM}$ ) and $\mathrm{MgCl}_{2}$ was added (to $10 \mathrm{mM}$ ) to all flasks to saturate the EDTA. EDDA was then added (to $200 \mu \mathrm{g} \mathrm{ml}^{-1}$ ) to all flasks. The flasks were then inoculated with the atypical strain MT525 (to a concentration of $2 \times 10^{7}$ cells ml ${ }^{-1}$ ) and growth was monitored for $30 \mathrm{~h}$ by $\mathrm{OD}_{540}$ measurement in a spectrophotometer.

Proteolytic degradation of Tf. A partially purified extracellular protease of the typical $A$. salmonicida strain MT004 (Lee \& Ellis, 1989) (approximately $100 \mu \mathrm{g} \mathrm{ml}^{-1}$ ) was incubated with an equal volume of bovine $\operatorname{Tf}\left(1 \mathrm{mg} \mathrm{ml}^{-1}\right)$ at $22^{\circ} \mathrm{C}$ for $2 \mathrm{~h}$ and samples were examined by SDS-PAGE.
SDSPAGE and Western blotting. To detect the proteolytic degradation of $\mathrm{Tf}$ by the partially purified $70 \mathrm{kDa}$ protease of the typical strain, samples were incubated with sample buffer $(1: 2, \mathrm{v} / \mathrm{v})$ comprising $4 \%(\mathrm{w} / \mathrm{v})$ SDS and $5 \%(\mathrm{v} / \mathrm{v}) 2$ -

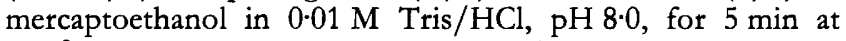
$100^{\circ} \mathrm{C}$. Aliquots $(20 \mu \mathrm{l})$ were subjected to PAGE in $4-30 \%$ gradient gels (Pharmacia-LKB) at $150 \mathrm{~V}$ for $170 \mathrm{~min}$ at $10^{\circ} \mathrm{C}$. Electrophoresis buffer ( $\mathrm{pH} \mathrm{7.4)}$ comprised $0.04 \mathrm{M}$ Tris $/ \mathrm{HCl}$, $0.02 \mathrm{M}$ sodium acetate, $0.002 \mathrm{M}$ EDTA and $0.2 \% \mathrm{SDS}$. Proteins were transferred to nitrocellulose $(0.45 \mu \mathrm{m}$; Bio-Rad) by electrophoresis at $30 \mathrm{~V}$ for $16 \mathrm{~h}$. Transfer buffer comprised $25 \mathrm{mM}$

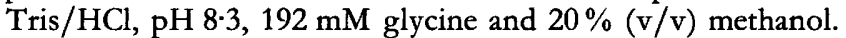
After transfer, nitrocellulose membranes were stained for total protein with colloidal gold (Aurodye, Amersham).

\section{RESULTS}

\section{Iron levels in Atlantic salmon}

The amount of iron present in Atlantic salmon serum was calculated to be $45 \cdot 2 \pm 14 \mu \mathrm{g} \mathrm{ml}^{-1}$ (mean $\pm \mathrm{SE}, n=10$ ). Using the bleomycin assay no free serum iron was detected.

\section{Growth of $A$. salmonicida in salmon serum}

The ability of two typical and one atypical strain of $A$. salmonicida to grow in heat-inactivated salmon serum was examined (Fig. 1). Both typical and atypical strains were capable of rapid growth in the serum.

\section{Utilization of Tf/Lfbound iron}

The ability of $A$. salmonicida to obtain iron bound to Tf and Lf was examined using a plate bioassay. Both typical

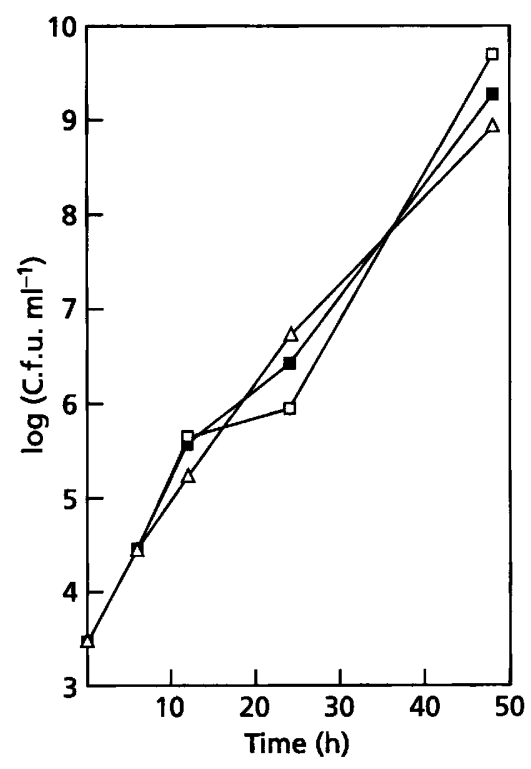

Fig. 1. Growth kinetics of $A$. salmonicida in heat-inactivated Atlantic salmon serum. $\square$, Typical strain MT004; $\square$, typical strain MT423; $\triangle$, atypical strain MT194. Results are means of triplicate values. 
Table 1. Utilization of non-haem iron proteins by Aeromonas salmonicida

Utilization of non-haem iron proteins was determined by measuring the zone of growth $(\mathrm{mm})$ around a $3 \mathrm{~mm}$ diameter well containing $30 \mu \mathrm{l}$ transferrin (Tf) or lactoferrin (Lf) on a plate containing TSA $+200 \mu \mathrm{g}$ EDDA ml ${ }^{-1}$ seeded with $10^{5}$ c.f.u. of one of six A. salmonicida strains. Human (H) or bovine (B) Tf or Lf was saturated to $30 \%$ or $90 \%$ with ferric citrate as indicated.

\begin{tabular}{|c|c|c|c|c|c|c|c|c|}
\hline \multirow[t]{3}{*}{ Strain* } & \multicolumn{8}{|c|}{ Utilization of } \\
\hline & \multicolumn{2}{|c|}{ HTf } & \multicolumn{2}{|c|}{ HLf } & \multicolumn{2}{|c|}{ BTf } & \multicolumn{2}{|c|}{ BLf } \\
\hline & $30 \%$ & $90 \%$ & $30 \%$ & $90 \%$ & $30 \%$ & $90 \%$ & $30 \%$ & $90 \%$ \\
\hline MT004 (T) & 6 & 22 & 6 & 23 & 7 & 24 & 5 & 23 \\
\hline MT616 (T) & 7 & 21 & 6 & 22 & 8 & 24 & 6 & 21 \\
\hline MT423 (T) & 7 & 21 & 6 & 23 & 8 & 23 & 6 & 20 \\
\hline MT486 (T) & 9 & 23 & 6 & 22 & 8 & 19 & 7 & 21 \\
\hline MT194 (A) & 4 & 23 & 5 & 23 & 5 & 20 & 4 & 20 \\
\hline MT525 (A) & 4 & 21 & 4 & 23 & 6 & 18 & 4 & 17 \\
\hline
\end{tabular}

*(T), typical strain; (A), atypical strain.

and atypical strains were able to utilize iron bound to human and bovine sources of $\mathrm{Tf}$ and Lf at 30\% iron saturation - the physiological saturation of $\mathrm{Tf}-$ and at $90 \%$ iron saturation (Table 1). Apo-forms of Tf and Lf did not support the growth of any of the strains although all of the strains were able to utilize $100 \mu \mathrm{M} \mathrm{FeCl}_{3}$ (data not shown).

\section{Siderophore-mediated utilization of Tf-bound iron}

The ability of the typical and atypical strains listed in Table 1 to utilize 'Tf-bound iron by a siderophoremediated mechanism was investigated. Growth kinetics of a representative typical and atypical strain of $A$. salmonicida in the presence of a growth-suppressive concentration of EDDA $\left(200 \mu \mathrm{g} \mathrm{m}^{-1}\right)$ are shown in Fig. 2. Results similar to those shown in Fig. 2(a) were obtained with all four typical strains and Fig. 2(b) is representative of both atypical strains. In both typical and atypical strains, suppression of growth imposed by EDDA was reversed to normal by the addition of $100 \mu \mathrm{M}$ $\mathrm{FeCl}_{3}$ (data not shown). The inhibition of growth was also reversed upon the addition of a $30 \%$ iron-saturated bovine Tf solution ( $1 \mathrm{mg} \mathrm{ml}^{-1}$ ) (Fig. 2). However, when the $30 \%$ iron-saturated Tf added was contained within a dialysis bag with a $10 \mathrm{kDa}$ molecular mass exclusion limit, the EDDA-imposed growth suppression was reversed only in the typical strain (Fig. 2a), while the growth of the atypical strains remained inhibited (Fig. 2b). The presence of a dialysis bag containing only growth medium had no effect on the growth of $A$. salmonicida in either iron-replete or iron-restricted media (data not shown). The results of the dialysis bag experiments suggest that a low molecular mass soluble factor is responsible for the utilization of Tfbound iron by typical strains. In contrast, it is possible that atypical strains lacking this soluble factor utilize Tfbound iron by a mechanism requiring direct contact between the bacterial cell surface and Tf and/or a proteolytic release of iron from $\mathrm{Tf}$.

\section{Tf-binding assays}

The six strains of $A$. salmonicida grown under iron restriction were used to determine whether Tf or Lf could interact directly with the cell surface of $A$. salmonicida via IROMPs. A solid-phase dot-blot enzyme assay was used in which either iron-replete or iron-restricted whole cells were immobilized on nitrocellulose membranes which were then probed with either HRP-Tf, HRP-Lf, bio-Tf or bio-Lf (followed by peroxidase-labelled streptavidin in the latter two cases) to detect either Tf- or Lf-binding activity. Using these binding assays on the four typical and two atypical strains listed in Table 1, it was not possible to detect the binding of Tf or Lf to whole cells. HRP-Tf/Lf and biotinylated Tf/Lf immobilized on nitrocellulose as positive controls gave a positive reaction when stained with 4-chloro-1-naphthol $/ \mathrm{H}_{2} \mathrm{O}_{2}$.

\section{Proteolytic degradation of Tf by atypical $A$. salmonicida ECP}

The effects of the ECP of the atypical $A$. salmonicida strain M'T525 on $30 \%$ saturated bovine Tf were examined in order to determine whether Tf-iron acquisition by atypical strains was mediated by a proteolytic degradation of $\mathrm{Tf}$. ECP of the atypical A. salmonicida strain MT525 possessed proteolytic activity due to the presence of a metalloprotease which was almost completely inhibited in the presence of $10 \mathrm{mM}$ EDTA. ECP incubated with bovine Tf enclosed in a dialysis bag reversed the growth inhibition imposed on the atypical $A$. salmonicida by the addition of EDDA (Fig. 3). The ECP of $A$. salmonicida MT525 alone or Tf alone had no effect on growth (data not shown). In a further experiment where EDTA was 

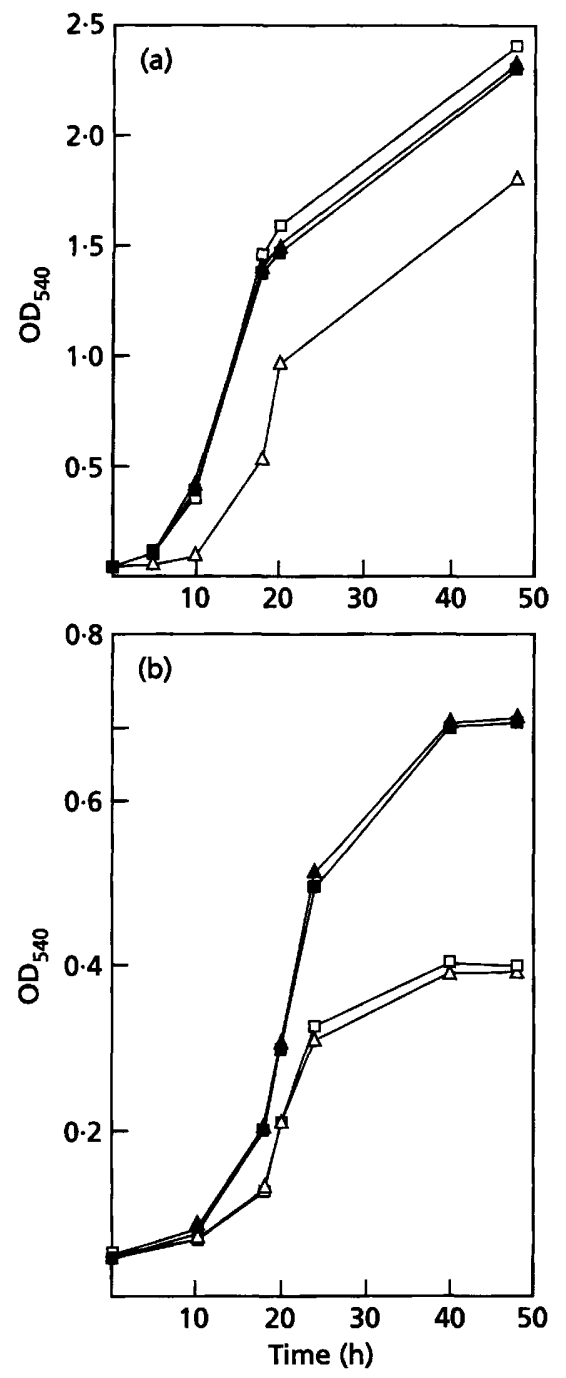

Fig. 2. Growth kinetics of $A$. salmonicida in TSB ( $\Delta$ ), TSB + EDDA $\left(200 \mu \mathrm{g} \mathrm{m}^{-1}\right)(\triangle)$, TSB + EDDA + 30\% bovine Tf $\left(1 \mathrm{mg} \mathrm{ml}^{-1}\right)(\mathrm{C})$ and TSB + EDDA + 30\% bovine Tf in dialysis bag $\left(5 \mathrm{mg} \mathrm{ml}^{-1}\right)(\square)$. Samples were taken at the times indicated and their $\mathrm{OD}_{540}$ measured. (a) Typical strain, MT004; (b) atypical strain, MT194. Data are means of duplicate values.

incorporated to inhibit the ECP proteolytic activity, the growth-stimulating effect of ECP plus Tf inside the dialysis bag was removed (Fig. 4).

\section{Release of iron from salmon serum by atypical $A$. salmonicida ECP}

In similar experiments to those using ECP and Tf in the dialysis bag, the conditioning of TSB by ECP and salmon serum within a dialysis bag reversed the suppressed growth rate imposed by EDDA (Fig. 4). However, the inhibition of ECP proteolytic activity by the presence of EDTA removed this effect (Fig. 4). The presence of ECP or salmon serum in the dialysis bag did not reverse the effect of EDDA (Fig. 4).

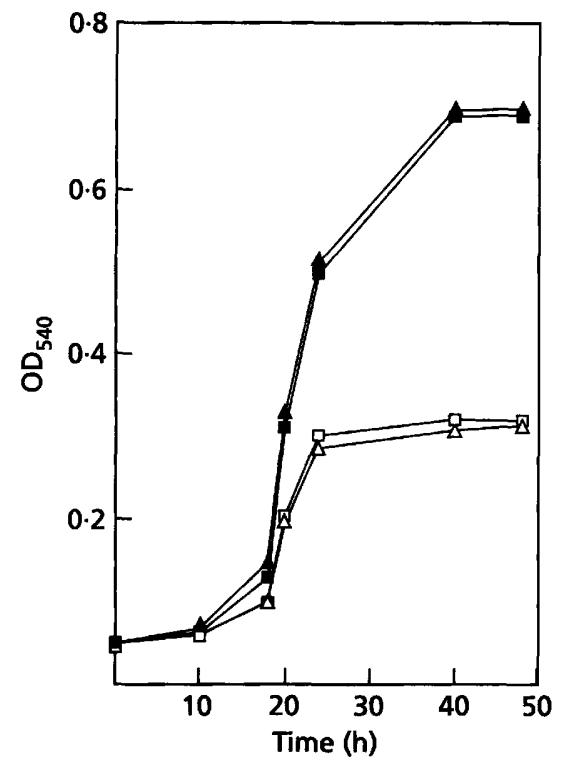

Fig. 3. Growth kinetics of atypical A. salmonicida MT525 in TSB + EDDA $\left(200 \mu \mathrm{g} \mathrm{ml}^{-1}\right)(\triangle)$, TSB + EDDA + 30\% bovine Tf $\left(1 \mathrm{mg} \mathrm{ml}^{-1}\right.$ ) ( $\left.\square\right)$, TSB + EDDA $+30 \%$ bovine Tf in dialysis bag $\left(5 \mathrm{mg} \mathrm{m}^{-1}\right)$ ( $\left.\square\right)$ and TSB + EDDA $+30 \%$ bovine Tf +ECP in dialysis bag $(\boldsymbol{A})$. Samples were taken at the times indicated and their $\mathrm{OD}_{540}$ measured. Data are means of duplicate values.

\section{Digestion of Tf by the $70 \mathrm{kDa}$ protease of a typical strain}

Similar experiments to determine whether the proteolytic degradation of Tf by ECP of typical strains of $A$. salmonicida was capable of reversing the growth suppression imposed by EDDA were not possible using dialysis bag experiments due to the presence of soluble siderophores capable of reversing growth suppression in the ECP of typical strains. As an alternative approach, a partially purified preparation of the extracellular $70 \mathrm{kDa}$ serine protease isolated from $A$. salmonicida MT004 was incubated with bovine $\mathrm{Tf}$ and then analysed by SDSPAGE. Although the preparation had undergone partial auto-digestion due to prolonged storage, all the proteolytic activity could be attributed to the serine protease because of total inhibition by PMSF. Analysis of the digest by SDS-PAGE indicated total digestion of Tf into a number of low molecular mass components (Fig. 5).

\section{DISCUSSION}

In a previous study we confirmed earlier reports that typical and atypical strains of $A$. salmonicida are able to grow and multiply under conditions of iron restriction. Typical strains of $A$. salmonicida possess an inducible siderophore-mediated iron uptake mechanism involving the production of a 2,3-diphenolcatechol siderophore while atypical strains of $A$. salmonicida possess an unidentified siderophore-independent iron uptake mechanism (Hirst et al., 1991). Chart \& Trust (1983) reported on one atypical strain of $A$. salmonicida which was able to use $\mathrm{Lf}$ as a source of iron but the mechanism did not 


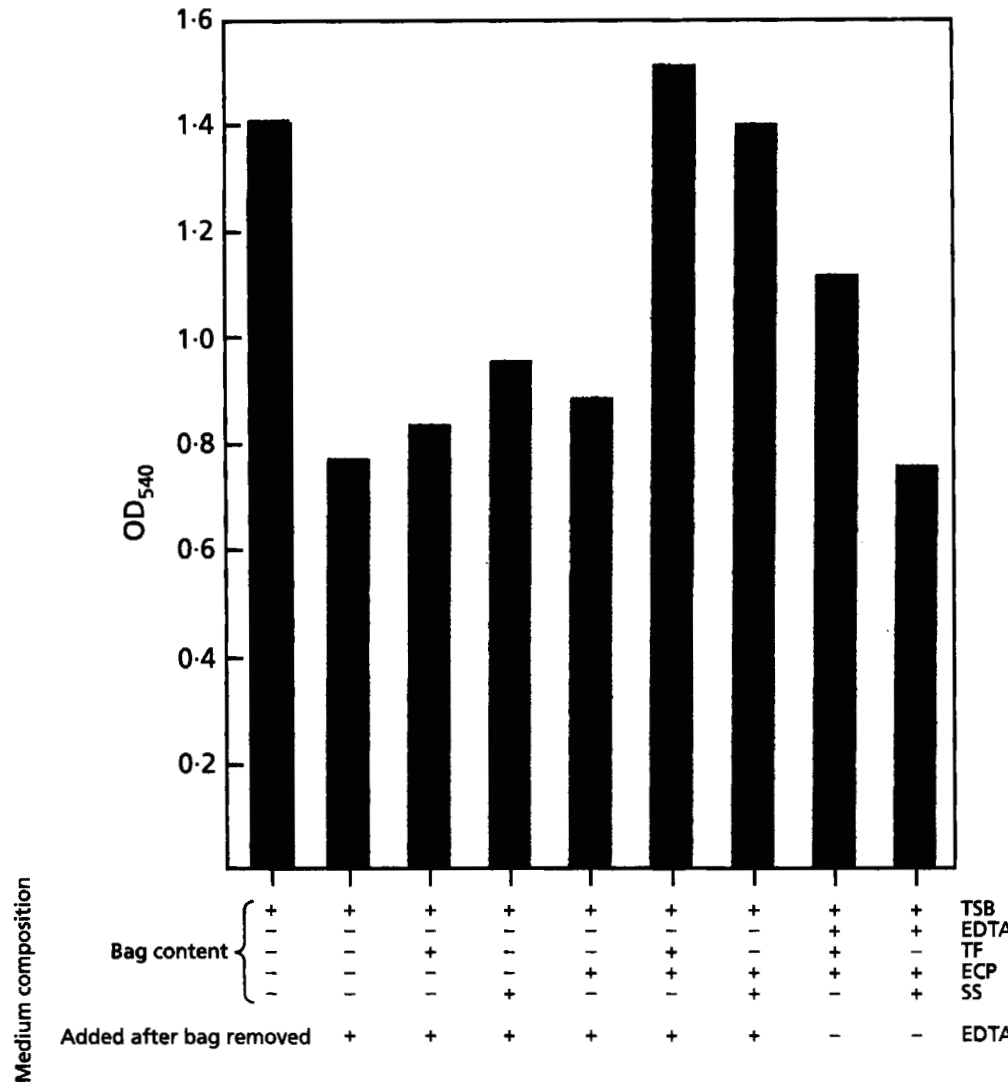

Fig. 4. Growth of atypical $A$. salmonicida MT525 in TSB which had previously been conditioned by immersion of dialysis bags containing: TSB; TSB and transferrin (Tf); TSB and salmon serum (SS); TSB and ECP; TSB plus Tf and ECP; TSB plus SS and ECP; TSB plus Tf, ECP and EDTA; TSB plus SS, ECP and EDTA. Following removal of the bags all media were equalized by addition of EDTA (as appropriate; indicated on figure), $\mathrm{MgCl}_{2}$ and EDDA. Results show the growth $\left(\mathrm{OD}_{540}\right)$ after $30 \mathrm{~h}$ incubation. Data are means of duplicate values.

apparently involve the production of a siderophore as the strain was unable to remove ${ }^{59} \mathrm{Fe}^{3+}$ bound to Lf across a dialysis membrane, suggesting that Lf utilization involved a direct interaction between If and the bacterial cell surface. A number of other non-siderophore-producing bacterial pathogens such as Neisseria meningitidis (Schryvers \& Morris, 1988), Haemophilus influenzae (Schryvers, 1988; Morton \& Williams, 1990), H. pleuropneumoniae (Niven et al., 1989), $H$. somnus (Ogunnariwo et al., 1990), Pasteurella baemolytica (Ogunnariwo \& Schryvers, 1990) and Bordetella pertussis (Redhead et al., 1987; Redhead \& Hill, 1991) are all able to acquire iron bound to Tf via direct cell surface interactions.

In the present study we showed that both typical and atypical strains of $A$. salmonicida were capable of rapid growth in heat-inactivated salmon serum, confirming observations by Ellis \& Stapleton (1988). There was no detectable free iron in the serum, as determined with the bleomycin assay of Gutteridge et al. (1981). The iron that was present $\left(45 \mu \mathrm{g} \mathrm{ml}^{-1}\right.$ ) was presumably bound by the host iron-binding proteins such as Tf (Congleton \& Wagner, 1991) and is comparable to the amounts found in mammalian serum (Persijn et al., 1971).

Using a plate bioassay it was demonstrated that both typical and atypical strains of $A$. salmonicida were able to utilize Tf- and Lf-bound iron from human and bovine sources and to utilize these iron-binding proteins at physiological levels of iron saturation. The ability of $A$. salmonicida to utilize Tf and Lf from mammalian sources differed from many other bacterial pathogens capable of utilizing Tf via direct cell surface interactions in that it is usual for this mechanism to be specific for the Tf of the host (Schryvers \& Gonzalez, 1990).

A solid-phase dot-blot enzyme assay was used to determine whether Tf utilization by typical and atypical strains involved Tf binding. Whole cells immobilized on nitrocellulose membranes were tested for their ability to bind HRP-Tf, HRP-Lf, bio-Tf or bio-Lf from different mammalian sources. These techniques, used to identify the specific cell surface Tf/Lf receptors in N. meningitidis, $H$. infuenzae and $P$. baemolytica, failed to identify such a receptor in $A$. salmonicida.

Using dialysis bag experiments, other possible mechanisms of Tf utilization by $A$. salmonicida were investigated. The suppression of growth imposed on typical and atypical strains by the addition of EDDA to the growth medium could be reversed by the addition of $30 \%$ iron-saturated bovine Tf. When the Tf was contained within a dialysis bag with a molecular mass exclusion limit of $10 \mathrm{kDa}$, the EDDA-imposed growth suppression of typical strains was still reversed, but growth of atypical strains remained suppressed. This observation confirms the ability of typical strains to utilize Tf-bound iron by a siderophore-mediated mechanism and is similar to the mechanism of Tf-bound iron acquisition described for motile Aeromonas species (Massad et al., 1991). Siderophores, being soluble and of low molecular mass (500-1000 Da), can pass through a dialysis mem- 


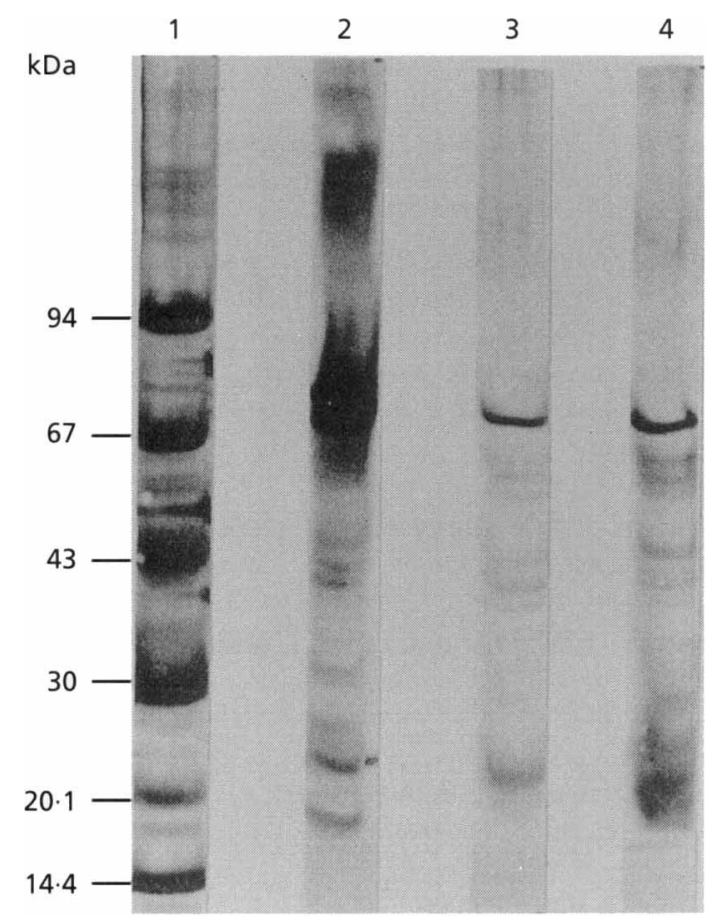

Fig. 5. SDS-PAGE of proteolytic digests of Tf. Proteins were detected by Western blotting and colloidal gold stain. Lane 1, low molecular mass protein standards; lane 2, bovine Tf; lane 3, partially purified $70 \mathrm{kDa}$ protease of typical $A$. salmonicida MT004; lane 4, Tf incubated with the $70 \mathrm{kDa}$ protease showing proteolytic digestion of Tf. The lanes were overloaded $(11 \mu \mathrm{g}$ protein per lane) in order to demonstrate the complete digestion of Tf.

brane to form complexes with iron. The inability of atypical strains to utilize Tf contained within a dialysis bag suggested some other mechanism.

An additional mechanism involved in the utilization of Tf-bound iron by pathogenic bacteria has been described by Griffiths (1987b); it involves the proteolytic degradation of $\mathrm{Tf}$ and disruption of the iron-binding site to release $\mathrm{Fe}^{3+}$. Such a mechanism has been described by Döring et al. (1988) for Pseudomonas aeruginosa, in which only in the presence of the secreted proteolytic enzyme elastase can the $P_{s}$. aeruginosa siderophore, pyoverdin, facilitate iron release and uptake from Tf. Since both typical and atypical strains of $A$. salmonicida produce extracellular proteases which are regarded as important virulence factors in the pathogenesis of $A$. salmonicida infection (Ellis, 1991), the possibility that proteolytic degradation of Tf may enable typical and atypical strains to utilize Tf-bound iron was investigated.

Experiments examining the ability of both extracellular products of an atypical strain, and of a partially purified extracellular protease of a typical strain, indicated that proteolytic degradation of $\mathrm{Tf}$ as a mechanism of $\mathrm{Tf}$-bound iron acquisition by $A$. salmonicida was possible. In atypical strains, ECP containing a metalloprotease was able to interact with Tf contained within a dialysis bag and reverse the growth suppression imposed on atypical $A$. salmonicida by EDDA; Tf or ECP alone contained within the dialysis bag did not reverse the growth suppression. Inhibition of the ECP proteolytic activity by incorporation of EDTA prevented the ability of the ECP to act upon $\mathrm{Tf}$ and release the iron in a form which was able to diffuse through the dialysis bag and stimulate growth of the iron-restricted bacteria. A similar effect was observed with ECP and salmon serum enclosed in the dialysis bag.

The extracellular serine protease produced by typical strains was found to be capable of degrading Tf, resulting in several low molecular mass components observed in SDS-PAGE. It is not known whether the proteolytic degradation described in this study resulted in the disruption of iron-binding sites with the release of $\mathrm{Fe}^{3+}$. It may be the case, as with the elastase produced by $P_{s}$. aeruginosa, that the serine protease facilitates the release of $\mathrm{Fe}^{3+}$ from Tf, enabling uptake by the siderophore produced by typical strains of $A$. salmonicida. However, the experiments with the atypical strain indicate that factors in the ECP which correlated with proteolytic activity can release iron from $\mathrm{Tf}$ and salmon serum, making it available for uptake in the absence of siderophores. In this regard, the observation by Neelam et al. (1993) that the production of the $70 \mathrm{kDa}$ protease by a typical strain grown in vitro under iron restriction was greatly enhanced, may have significance in the utilization of host Tf during infection.

\section{ACKNOWLEDGEMENTS}

This work was partly funded by the Crown Estates Commission and the Scottish Salmon Growers Association. Thanks are also expressed to Mr I. Imaz for technical assistance and $\mathrm{Dr}$ T. S. Hastings for helpful discussions.

\section{REFERENCES}

Aisen, P., Liebman, A. \& Zweier, J. (1978). Stoichiometric and site characteristics of the binding of iron to human transferrin. $J$ Biol Chem 253, 1930-1937.

Aoki, T. \& Holland, B. I. (1985). The outer membrane proteins of the fish pathogens Aeromonas bydrophila, Aeromonas salmonicida and Edwardsiella tarda. FEMS Microbiol Lett 27, 299-305.

Avrameas, S., Ternynch, T. \& Guesdon, J. L. (1979). Coupling of enzymes to antibodies and antigens. Scand J Immunol 8, 7-23.

Bezkorovainy, A. (1987). Iron proteins. In Iron and InfectionMolecular, Pbysiological and Clinical Aspects, pp. 27-67. Edited by J. J. Bullen \& E. Griffiths. Chichester: John Wiley \& Sons.

Bullen, J. J. (1981). The significance of iron in infection. Rev Infect Dis 3, 1127-1138.

Chart, H. \& Griffiths, E. (1985). Antigenic and molecular homology of the ferric enterobactin receptor protein of Escherichia coli. J Gen Microbiol 131, 1503-1509.

Chart, H. \& Trust, T. J. (1983). Acquisition of iron by Aeromonas salmonicida. J Bacteriol 156, 758-764.

Congleton, J. L. \& Wagner, E. J. (1991). Acute-phase hypoferremic response to lipopolysaccharide in rainbow trout (Oncorbynchus mykiss). Comp Biochem Pbysiol 98A, 195-200.

Donachie, W. \& Gilmour, N. J. L. (1988). Sheep antibody response to cell wall ancigens expressed in vivo by Pasteurella baemolytica. FEMS Microbiol Lett 56, 271-276. 
Dorring, G., Pfestorf, M., Botzenhart, K. \& Abdallah, M. A. (1988). Impact of proteases on iron uptake of Pseudomonas aeruginosa pyoverdin from transferrin and lactoferrin. Infect Immun 56, 291-293.

Ellis, A. E. (1991). An appraisal of the extracellular toxins of Aeromonas salmonicida subspecies salmonicida. J Fish Dis 14, 265-277.

Ellis. A. E. \& Stapleton, K. J. (1988). Differential susceptibility of salmonid fishes to furunculosis correlates with differential serum enhancement of Aeromonas salmonicida extracellular protease activity. Microb Pathog 4, 299-304.

Graham, G. \& Bates, G. W. (1976). Approaches to the standardisation of serum unsaturated iron-binding capacity. J Lab Clin Med 88, 477-486.

Griffiths, E. (1987a). Iron in biological systems. In Iron and Infection - Molecular, Pbysiological and Clinical Aspects, pp. 1-25. Edited by J. J. Bullen \& E. Griffiths. Chichester: John Wiley \& Sons.

Griffiths, E. (1987b). The iron-uptake systems of pathogenic bacteria. In Iron and Infection-Molecular, Physiological and Clinical Aspects, pp. 69-137. Edited by J. J. Bullen \& E. Griffiths. Chichester: John Wiley \& Sons.

Griffiths, E. \& Humphreys, J. (1980). Isolation of enterochelin from the peritoneal washings of guinea pigs lethally infected with Escherichia coli. Infect Immun 28, 286-289.

Griffiths, E., Chart, H. \& Stevenson, P. (1988). High affinity iron uptake systems and bacterial virulence. In Virulence Mechanisms of Bacterial Patbogens, pp. 121-137. Edited by J. A. Roth. Washington, DC: American Society for Microbiology.

Gudmundsdottir, B. K., Hastings, T. S. \& Ellis, A. E. (1990). Isolation of a new toxic protease from a strain of Aeromonas salmonicida subspecies achromogenes. Dis Aquat $\operatorname{Org}$ 9, 199-208.

Gutteridge, J. M. C., Rowley, D. A. \& Halliwell, B. (1981). Superoxide dependent formation of hydroxyl radicals in the presence of iron salts. Biochem J 199, 263-265.

Hirst, I. D. \& Ellis, A. E. (1994). Iron-regulated outer membrane proteins of Aeromonas salmonicida are important protective antigens in Atlantic salmon against furunculosis. Fish \& Shellfish Immunol 4, $29-45$.

Hirst, I. D., Hastings, T. S. \& Ellis, A. E. (1991). Siderophore production by Aeromonas salmonicida. J Gen Microbiol 137, 1185-1192.

Lee, K.-K. \& Ellis, A. E. (1989). The quantitative relationship of lethality between extracellular protease and haemolysin of Aeromonas salmonicida in Atlantic salmon, Salmo salar. FEMS Microbiol Lett 61, 127-132.

McCarthy, D. H. \& Roberts, R. J. (1980). Furunculosis of fish - the present state of our knowledge. In Advances in Aquatic Microbiology, pp. 293-341. Edited by M. R. Droop \& H. W. Jannasch. London: Academic Press.

Martinez, J. L., Delgado-Iribarren, A. \& Baquero, F. (1990). Mechanisms of iron acquisition and bacterial virulence. FEMS Microbiol Rev 75, 45-56.
Massad, G., Arceneaux, J. E. L. \& Byers, B. R. (1991). Acquisition of iron from host sources by mesophilic Aeromonas species. $J \mathrm{Gen}$ Microbiol 137, 237-241.

Morton, D. J. \& Williams, P. (1990). Siderophore-independent acquisition of transfertin-bound iron by Haemophilus influenzae type b. J Gen Microbiol 136, 927-933.

Neelam, B., Robinson, R. A., Price, N. A. \& Stevens, L. (1993). The effect of iron limitation on the growth of Aeromonas salmonicida. Microbios 74, 59-67.

Niven, D. F., Donga, J. \& Archibald, F. S. (1989). Responses of Haemopbilus pleuropneumoniae to iron restrictions: changes in the outer membrane protein profile and the removal of iron from porcine transferrin. Mol Microbiol 1083-1089.

Ogunnariwo, J. A. \& Schryvers, A. B. (1990). Iron acquisition in Pasteurella baemolytica: expression and identification of a bovinespecific transferrin receptor. Infect Immun 58, 2091-2097.

Ogunnariwo, J. W., Cheng, C., Ford, J. \& Schryvers, A. B. (1990). Response of Haemophilus somnus to iron-limitation: expression and identification of a bovine-specific transferrin receptor. Microb Pathog 9, 397-406.

Persijn, J. P., van der Slik, W. \& Reithorst, A. (1971). Determination of serum iron and latent-binding capacity. Clin Cbim Acta 35, 91-98.

Redhead, K. \& Hill, T. (1991). Acquisition of iron from transferrin by Bordetella pertussis. FEMS Microbiol Lett 77, 303-308.

Redhead, K., Hill, T. \& Chart, H. (1987). Interaction of lactoferrin and transferrins with the outer membrane of Bordetella pertussis. $J$ Gen Microbiol 133, 891-898.

Rogers, H. J. (1973). Iron-binding catechols and virulence in Escherichia coli. Infect Immun 7, 445-456.

Schryvers, A. B. (1988). Characterisation of the human transferrin and lactoferrin receptors in Haemophilus influenzae. Mol Microbiol 2, 467-472.

Schryvers, A. B. \& Morris, L. J. (1988). Identification and characterisation of the transferrin receptor from Neisseria meningitidis. Mol Microbiol 2, 281-288.

Schryvers, A. B. \& Gonzalez, G. C. (1990). Receptors for transferrin in pathogenic bacteria are specific for the host's proteins. Can J Microbiol 36, 145-147.

Sciortino, C. V. \& Finkelstein, R. A. (1983). Vibrio cholerae expresses iron-regulated outer membrane proteins in vivo. Infect Immun 42, 990-996

Smith, H. (1990). Pathogenicity and the microbe in vivo. $J$ Gen Microbiol 136, 377-383.

Wolf, M. K. \& Crosa, J. H. (1986). Evidence for the role of a siderophore in promoting Vibrio anguillarum infection. $J$ Gen Microbiol 132, 2949-2952.

Received 5 February 1996; accepted 8 February 1996. 